\title{
Human Amniotic Allograft in Use on Talar Dome Lesions: A Prospective Report of 37 Patients
}

\author{
John Joseph Anderson', Zflan Swayzee1, Myron Holbert Hansen ${ }^{2}$ \\ ${ }^{1}$ New Mexico Bone and Joint Institute, Alamogordo, USA \\ ${ }^{2}$ Private Practice-Cactus Foot and Ankle, Chandler, USA \\ Email: jiosephanderson5@gmail.com, hansenmyron@hotmail.com
}

Received 24 April 2014; revised 20 May 2014; accepted 16 June 2014

Copyright (C) 2014 by authors and Scientific Research Publishing Inc.

This work is licensed under the Creative Commons Attribution International License (CC BY).

http://creativecommons.org/licenses/by/4.0/

c) (i) Open Access

\section{Abstract}

One of the most challenging joint conditions facing ankle surgeons today is the treatment of Osteochondritis Dissecans (OCD) of the talar dome. The use of human amniotic allograft (HAA) in various surgical procedures, has been proven to facilitate bone growth and both soft tissue and cartilage healing. The authors of this paper propose the addition of HAA to the surgical repair of talar dome lesions to improve postoperative results, specifically pain reduction. For the study, 37 patients were identified having an OCD lesion of the talus measuring no larger than $2 \mathrm{~cm}^{2}$. All patients were treated surgically with an arthroscopic micro-fracture repair along with the addition of HHA. Modified ACFAS ankle scores were taken pre-operatively and at 3 months, 12 months, and at 24 months postoperatively. Visual analog scores were also taken preoperative and 24 months postoperatively. The size of the talar lesions documented with pre-operative MRI's was compared with intra-operative measurements for each patient. Additional surgical repairs, comorbidities and any complications were also recorded and evaluated. All patients were treated with micro-fracture with HAA. Postoperative ACFAS scores for 3 months, 12 months and 24 months were significantly improved $(p<0.0001)$ compared with average preoperative scores. Additionally, VAS scores were also significantly improved when comparing the average pre-operative (4.9) and post-operative $(1.1)$ pain scores $(p<0.0001)$. The size of the lesions documented by pre-operative MRI correlated to intra-operative measurements. There were no identified complications. The addition of HAA to arthroscopic micro-fracture repair of talar dome lesions measuring less than 2 $\mathbf{c m}^{2}$ has shown to significantly improve both post-operative VAS scores, when compared to preoperative scores. This improvement in ACFAS and VAS scores speaks to the potential use of HAA in the treatment of $O C D$.

\section{Keywords}

Bone Lesions, Human Amniotic Allograft, Ankle Arthroscopy, Talus Fractures, Cartilage 


\section{Restoration, Stem Cells}

\section{Introduction}

Osteochondritis dissecans (OCD) broadly relates to loose bodies within a joint, in this particular study, the ankle joint. Kappis in 1922 and Rendu in the 1932 described and reported OCD relating specifically to talar fractures [1] [2]. Berndt and Hardy classification system was described in 1959 and as trans-chondral fractures (TCF) that were associated with some type of traumatic event. Due to the functional demand of the ankle, even small lesions can become very symptomatic resulting in the need of surgical repair. Several surgical methods have been described such as a simple arthroscopic debridement with micro-fracture to open osteo-chondral grafting to ankle joint fusion or ankle arthroplasty [3]-[5]. Because of the weight baring function and the vascular status of the talus, it is generally believed that small lesions are best treated with a less invasive surgical approach.

Human amniotic allograft (HAA) was used early for skin repair such as burns, ulcers and open lesions with very good results was documented as early as 1910 [6]-[11]. It has also been used in eyes for conjunctiva defects with great success [12]. HAA was first used internally in 1938 by Shimburg to stabilize the lumbar spine [13]. Later uses included repairing hip joints by Volkov with moderate success, along with other joints [14]. The versatility of amniotic allograft allows it to form few adhesions which allowed it to replace parietal peritoneum as demonstrated in 1975, which opened up the use to a larger field of modern study [15]. Initially, the use of these products had several complications resulting from tissue disease and infection transfer. Advances in technology have delivered a safe and consistent product over the last two decades. As a result, the variable form, uses and results of HAA have increased to the point they may compete with today's gold standard of allografts [16]-[22]. The stem cells present in HAA tissue are thought to have some level of immune privilege as well as being considered multipotent, meaning they can differentiate into various tissue types including muscle, tendon, bone or cartilage [23]. Additionally, the amniotic tissues are comprised of various types of collagen, hyaluronan and glycosaminoglycan and are thought to be a reservoir for growth factors [23]. The authors are confident that with the improvements that have been made in more recent years with HAA processing, clinicians are beginning to learn the potential benefits that the undifferentiated tissues can have on the healing process.

The authors have used amniotic or human allograft derived from amniotic tissue in several surgical applications with exceptional results [24]. With previous success, we applied these principals to using HAA to improve the body's ability to recover and replace tissue from simple fibrocartilage to a more quality cartilage defect replacement such as a mix of hyaline or fiber cartilage [19] [20]. Although OCD lesions are relatively rare and account for a very few talus and ankle fractures, it was felt that allograft HAA could be applied to arthroscopic treated lesions and positively enhance the long term outcome, and that this potential should be evaluated via prospective study.

\section{Patients and Methods}

37 patients with OCD lesions treated with arthroscopic micro-fracture along with HAA were selected from August 2008 to March 2012. Modified ACFAS ankle scores were collected prior to any surgical treatment, and post-operatively at 3 months, 12 months and at 24 months. Visual analog pain scores (VAS) were also taken prior to surgery and post-operative at 24 months. Most patients had pre and post-operative physical therapy, measured in weeks.

There were 488 ankle scopes available for review, 129 of those patients met inclusion criteria which consisted of talar dome lesions less than $2 \mathrm{~cm}^{2}$. Of these, any patient having had additional procedures such has peroneal tendon relocation, tibial, fibular, or talar exostectomies not done arthroscopically were eliminated. Two patients were lost due to follow-up and not included in the results.

\section{Operative Technique}

The ankle arthroscopy was performed with standard medial and lateral portals. All ankles were distracted with a standard uniform distraction technique. All limbs had thigh tourniquet used at $300 \mathrm{~mm} / \mathrm{hg}$. A pre-emptive proximal ankle block was given to all patients. All ankles were inspected, and a generalized synovectomy was 
done as indicated. As needed, a medial to lateral debridement and exostectomy of the anterior lip of the tibia was performed. Care was taken to assure no residual kissing lesions remaining on the tibial-talar interface. The talar dome lesion was identified and correlated to size and location on the MRI (Figure 1, Figure 2). A circumferential debridement was done to the subchondral level. A micro-fracture awl was used to perform the microfracturing of the lesion (Figure 3). Liquid form HAA* was used and applied directly to the lesion via needle technique and under direct visualization. Instruments were removed and portals were closed. The patient was then placed in an ankle stirrup splint until first post-op visit.

\section{Human Amniotic Allograft (HAA) Information}

The human amniotic allograft (HAA) used in this study is a commercial product that is composed of human amniotic membrane and cells from the amniotic fluid*. The cells from the amniotic fluid include multipotential stem cells that have been shown to be capable of differentiation into a variety of tissue types including bone, muscle, cartilage, and tendon, among others. Additionally these tissues are rich in various growth factors including morphogenic proteins, hyaluronic acid, collagen precursors and proteoglycans [25]-[28]. There is no an-

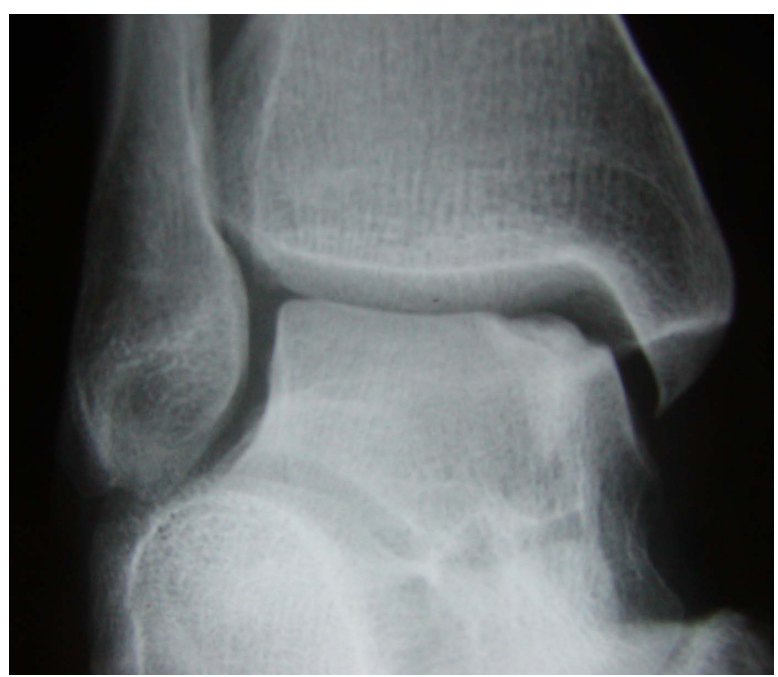

Figure 1. Osteochondritis dissecans of the medial talar dome pre-operatively.

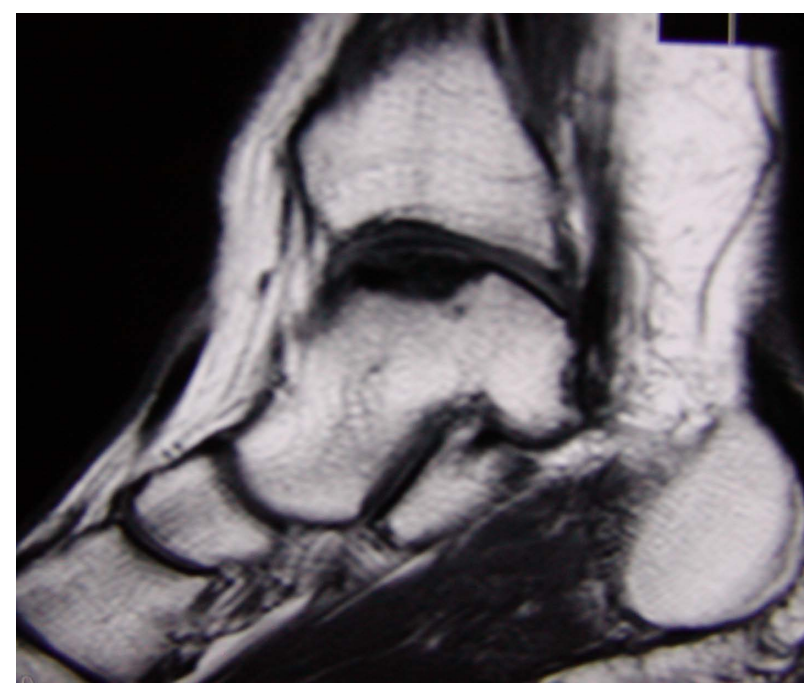

Figure 2. MRI of the talar dome lesion pre-operatively.

"2ccs liquid NuCel ${ }^{\circledR}$, NuTech Medical, Inc., Birmingham, AL. 


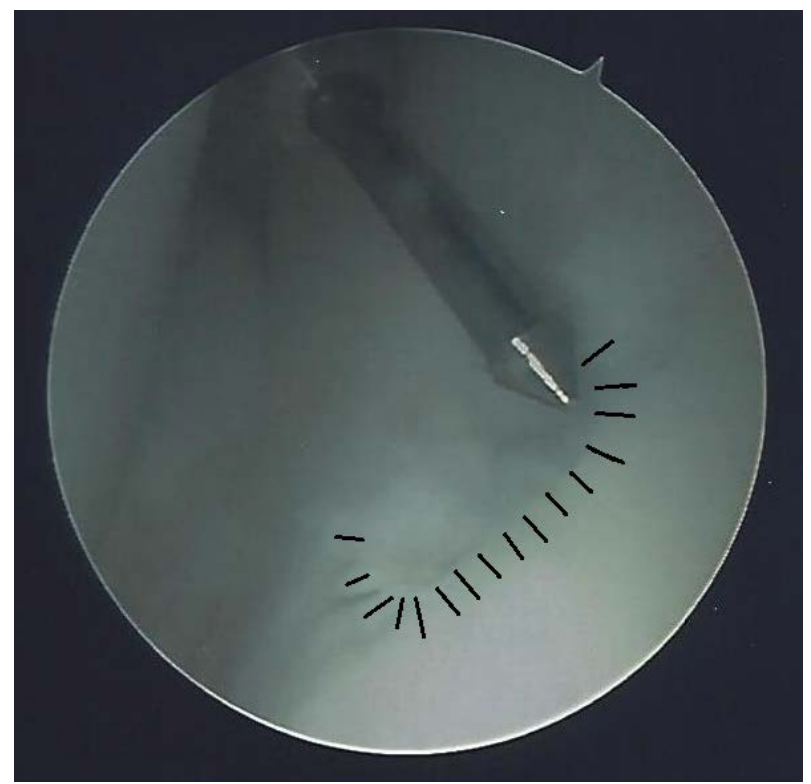

Figure 3. Typical OCD with micro-fracture awl prior to application of liquid human amniotic allograft.

tigenicity for the allograft due to the process of extracting amnion from the placental tissue [6] [11] [17] [19] [21] [22]. All harvested grafts are tested for HIV, hepatitis, HTVL and other diseases that are specific to processing. Each patient is also screened before donations can be collected.

\section{Results}

The average age for the patients was 49.6 years. There were 22 females (59.5\%) and 15 males (40.5\%) participating in the study. The average physical therapy for the group was 3 weeks pre-op and 4.3 weeks post-op. The average pre-operative ACFAS score was 73.1, 89.6 for 3-month post-op, 91.8 for 12 months post-op and 88.8 for 24 months post-op ( $\mathrm{p}<0.0001$ for each post-op scores to the pre-op score). The average VAS scores were 4.9 pre-operatively and 1.1 post-operatively which was a significant pain improvement $(\mathrm{p}<0.0001)$. The patient average size of the defect or bone edema from MRI scans was $1.9 \mathrm{~cm}$ and $1.3 \mathrm{~cm}$ intra-operatively, measured with a surgical ruler. There were 13 patients with one or more comorbidities, such as diabetes without neuropathy or hypertension. There were no identified post-surgical complications (Table 1).

\section{Discussion}

This prospective study shows that patients do significantly better overall from their pre-operative status with arthroscopic treated talar dome lesions less than $2 \mathrm{~cm}^{2}$ using micro-fracture and adjunctive human amniotic allograft. While the use of HAA has not been delineated as far as the techniques and applications in the ankle joint, it is accepted and has shown to be an effective allograft and a naïve tissue in which its potential to differentiate can assists in healing [23]. Possibly as an adjunct to further intervention, it is felt that this will allow hyaline cartilage development and the potential to develop into a more significant structural cartilage [25] [27]. The long term efficacy and analysis cannot be derived based solely on this prospective application in the 37 patients. It would appear that there is a significant benefit in patient outcome, which may improve the long term prognosis in these patients with progressive ankle joint arthrosis.

\section{Conclusion}

There will be continued application of human amniotic tissues within the role of allograft applications in the human body. The true role of this allograft tissue has not been fully ascertained; however, from this prospective study, it may be suggested that there is a role when applied to arthroscopically treated talar dome lesions less than $2 \mathrm{~cm}^{2}$. There were no complications associated with the use of amniotic tissues with any of the patients and 
Table 1. Patient demographics with relevant p-values.

\begin{tabular}{lcccccccccc}
\hline & \multicolumn{3}{c}{ Physical Therapy (Weeks) } & \multicolumn{3}{c}{ VAS Pain Score } & \multicolumn{4}{c}{ ACFAS Score } \\
\hline & Age & Pre-op & Post-op & Pre-op & Post-op (24 months) & Pre-op & 3 Months & 12 Months & 24 Months \\
Average & 49.97 & 3 & 4.27 & 4.92 & 1.14 & 73.081 & 89.57 & 91.89 & 88.86 \\
p values & & & & & ${ }^{*} 1 \mathrm{E}-18$ & ${ }^{* *}$ & $7 \mathrm{E}-18$ & $3 \mathrm{E}-22$ & $4 \mathrm{E}-18$ \\
\hline
\end{tabular}

${ }^{*} \mathrm{p}$ value comparing the VAS pre-operative score to the post-operative score at 24 months; ${ }^{* *} \mathrm{p}$ values comparing the ACFAS pre-operative to post-operative score at determined intervals.

this supports the continued use and safety in patients. Limitations would include the lack of a control group to compare all the data to as well as a limited number of patients that meet the inclusion criteria where an allograft would be necessary and useful. This study would serve as a basis for larger applications of both more solid type grafts of amniotic based tissues and also applications in other joints with similar chondral defects. The authors look forward to a greater than five-year follow up study on this or similar patient groups to evaluate the true role of amniotic tissue while combined with micro-fracture techniques and treating of OCD lesions of the talus. In future studies, the authors plan to compare these patients to a similar group with talar dome lesions using micro-fracture technique without HAA. This type of controlled study will serve as an additional step in evaluating the use of HAA in similar surgeries and other surgical disciplines.

\section{References}

[1] Kappis, M. (1922) Weitere Beiträgezur Traumatisch-Mechanischen Entstehung der "Spontanen” Knorpelablösungen (Sogen. Osteochondritis Dissecans). Deutsche Zeitschrift für Chirurgie, 171, 13-29. http://dx.doi.org/10.1007/BF02812921

[2] Rendu, A. (1932) Fracture Intra-articulaireparcellaire de la poûlieastraglienne. Lyon Médical, 150, 220.

[3] Yvars, M.F. (1975) Osteochondral Fractures of the Dome of the Talus. Clinical Orthopaedics and Related Research, 114, 185-191.

[4] Kelbérine, F. and Frank, A. (1998) Arthroscopic Treatment of Osteochondral Lesions of the Talar Dome: A Retrospective Study of 48 Cases. Arthroscopy: Journal of Arthroscopic \& Related Surgery, 15, 77-84. http://dx.doi.org/10.1053/ar.1999.v15.0150071

[5] Angermann, P. and Jensen, P. (1989) Osteochondritis Dissecans of the Talus: Long-Term Results of Surgical Treatment. Foot \& Ankle, 10, 161-163. http://dx.doi.org/10.1177/107110078901000309

[6] Hatch, E.L. (1999) Burns and Bravery. In: Hatch, E.L., Ed., Médico: My Life as a Country Doctor in Mexico, 193-195.

[7] Gwei-Djen, L. and Needham, J. (1964) Medieval Preparations of Urinary Steroid Hormones. IntJ Hist Med., 8, 101-121. http://dx.doi.org/10.1017/S0025727300029355

[8] Davis, S. (1910) Skin Transplantation: With a Review of 550 Cases at the Johns Hopkins Hospital. Johns Hopkins Hosp Rep Ba/t, 15, 307-396.

[9] Sabella, N. (1913) Use of the Fetal Membranes in Skin Grafting. Medication Reconciliation NY, 83, 478-480.

[10] Stern, M. (1913) The Grafting of Preserved Amniotic Membrane to Burned and Ulcerated Surfaces. Substituting Skin Grafts. JAMA, 60, 973-974. http://dx.doi.org/10.1001/jama.1913.04340130021008

[11] Douglas, B. (1952) Homografts of Fetal Membranes as a Covering for Large Wounds-Especially Those from Burns: An Experimental and Clinical Study (Preliminary Report). Journal of the Tennessee Medical Association, 45, $230-235$.

[12] deRotth, A. (1940) Plastic Repair of Conjunctival Defects with Fetal Membranes. Archives of Ophthalmology, 23, 522-525.

[13] Shimberg, M. (1938) The Use of Amniotic-Fluid Concentrates in Orthopaedic Conditions. Journal of Bone and Joint Surgery, 20, 167-177.

[14] Volkov, M.V. (1973) Arthroplasty of Joints Using Amniotic Membrane. In: Chapchal, G., Ed., Arthroplasty of the Hip: 5th International Symposium 1972 in Nijmegen Netherlands, Georg Thieme, Stuttgart.

[15] Trelford, J.D., Hanson, F.W., Anderson, D.C. and Mendel, V.E. (1975) Amnion Autografts, Permanent Structure. J Med, 6, 243-247.

[16] Anderson, J.J. (2009) Bone Grafting and Orthobiologics for Reconstruction of the Diabetic Lower Extremity. In: Zgonis, T., Ed., Surgical Reconstruction of the Diabetic Foot and Ankle, Lippincott Williams \& Wilkins, Philadelphia, 192-193.

[17] Cornell, C.N. (1999) Osteoconductive Materials and Their Role as Substitutes for Autogenous Bone Grafts. Orthoped- 
ic Clinics of North America, 30, 591-598. http://dx.doi.org/10.1016/S0030-5898(05)70112-7

[18] Weinraub, G.M. (2005) Orthobiologics: A Survey of Materials and Techniques. Clinics in Podiatric Medicine and Surgery, 22, 509-519. http://dx.doi.org/10.1016/j.cpm.2005.08.003

[19] Lane, J.M. and Bromstrom, M.P.G. (1998) Bone Grafting and New Composite Biosynthestic Graft Materials. AAOS Instructional Course Lectures, 47, 525-534.

[20] Martin, R.B., Chapman, M.W., Sharkey, N.A., et al. (1995) Bone in Growth and Mechanical Properties of Coralline Hydroxyapatite 1 Year from Implantation. Biomaterials, 14, 341-348. http://dx.doi.org/10.1016/0142-9612(93)90052-4

[21] Anderson, J.J., Boone, J.J., Hansen, M., Brady, C., Gough, A. and Fowler, Z. (2013) Ankle Arthrodesis Fusion Rates for Mesenchymal Stem Cell Bone Allograft Verses Proximal Tibia Autograft. Journal of the American Podiatric Medical Association, Submitted June.

[22] Anderson, J.J., Jeppesen, N.S., Hansen, M., Brady, C., Gough, A. and Fowler, Z. (2013) First Metatarsophalangeal Joint Arthrodesis: Comparison of Mesenchymal Stem Cell Allograft versus Autogenous Bone Graft Fusion Rates. Surgical Science, 4.

[23] Sachs, B.P. and Stern, C.M. (1979) Activity and Characterization of a Low Molecular Fraction Present in Human Amniotic Fluid with Broad Spectrum Antibacterial Activity. British Journal of Obstetrics and Gynaecology, 86, 81-86. http://dx.doi.org/10.1111/j.1471-0528.1979.tb10572.x

[24] Anderson, J.J., Gough, A.F., Hansen, M.H. and Swayzee, Z. (2014) Initial Experience with Tricortical Iliac Crest Bone Graft and Human Amniotic Allograft in Evans Calcaneal Osteotomy. Journal of the American Podiatric Medical Association.

[25] Davitt, J.S., MacWilliams, B.A. and Armstrong, P.F. (2001) Plantar Pressure and Radiographic Changes after Distal Calcaneal Legthening in Children and Adolescents. Journal of Pediatric Orthopaedics, 21, 70-75. http://dx.doi.org/10.1097/01241398-200101000-00015

[26] NuTech Medical (2012) NuCel: Multipotential Cellular Matrix (HCT/P). 1, 1-2.

[27] NuTech Medical (2012) NuCel: Product Overview. 1, 1-2.

[28] Sato, T.A., Keelan, J.A. and Mitchel, M.D. (2003) Critical Paracrine Interactions between TNF- $\alpha$ and IL-10 Regulate Lipopolysaccharide-Stimulated Human Choriodecidual Cytokine and Prostaglandin $E_{2}$ Production. The Journal of Immunology, 170, 158-166. http://dx.doi.org/10.4049/jimmunol.170.1.158 
Scientific Research Publishing (SCIRP) is one of the largest Open Access journal publishers. It is currently publishing more than 200 open access, online, peer-reviewed journals covering a wide range of academic disciplines. SCIRP serves the worldwide academic communities and contributes to the progress and application of science with its publication.

Other selected journals from SCIRP are listed as below. Submit your manuscript to us via either submit@scirp.org or Online Submission Portal.
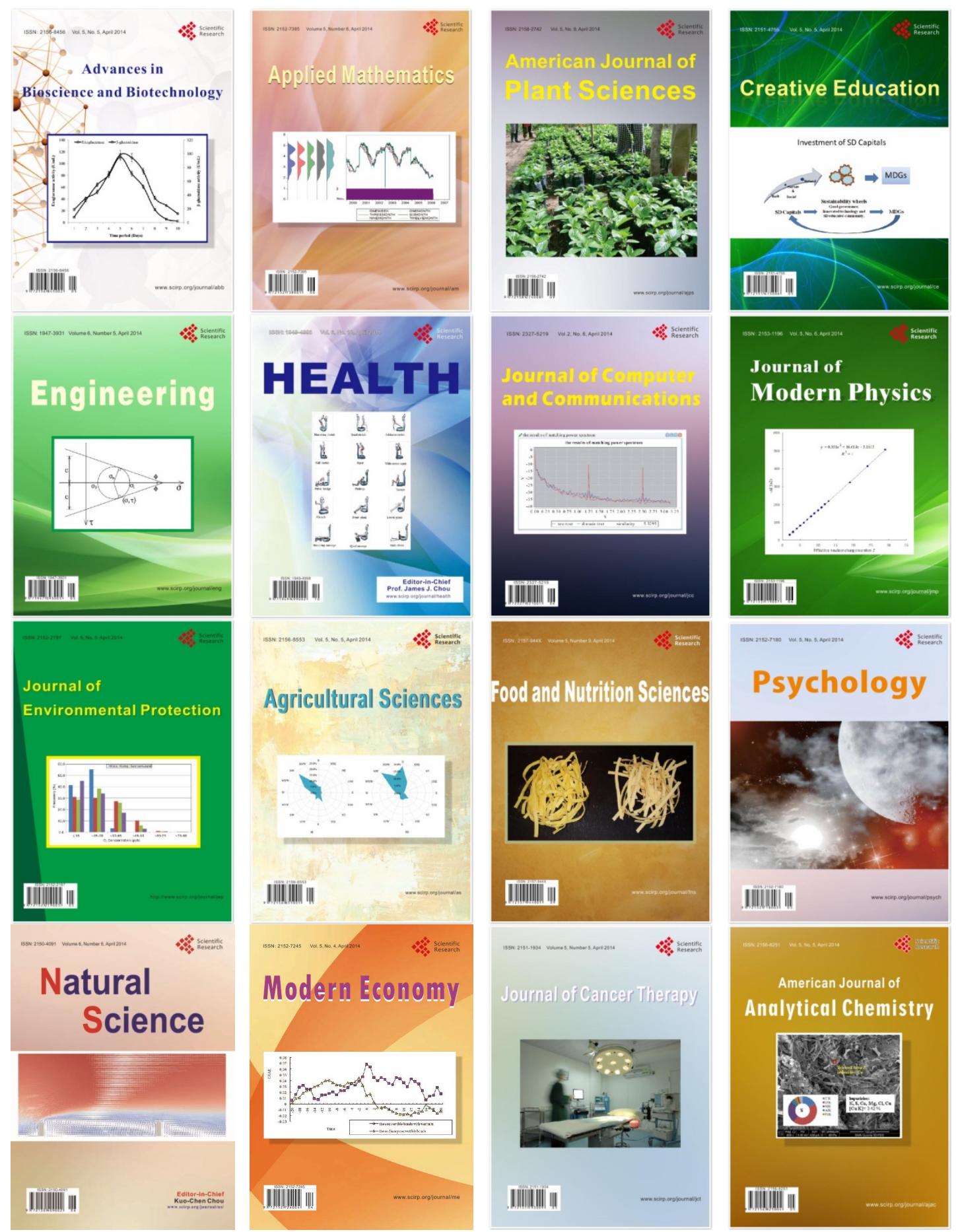